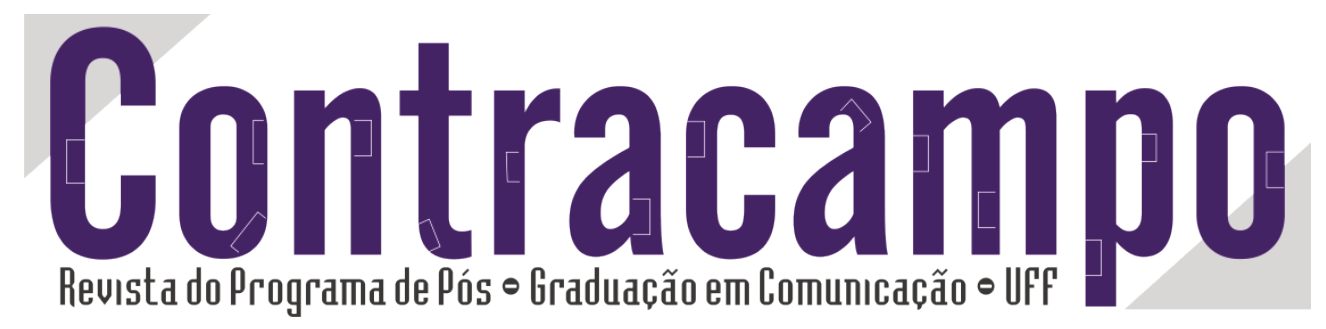

\title{
Apropriar-se da materialidade: (re)visitar a história da escrita e do impresso no Brasil
}

\author{
Appropriating materiality: (re)visiting the history of \\ writing and print in Brazil
}

Bruno Guimarães Martins

bruno.morca@gmail.com

Professor Adjunto do Departamento de Comunicação Social da Universidade Federal de Minas Gerais (UFMG), Brasil.

Fonte de financiamento: este artigo faz parte do projeto "Artífices, tipógrafos, editores: (re)visitar a história da imprensa nas Minas oitocentistas", financiado pelo CNPq.

\section{PPGCOM T-m}

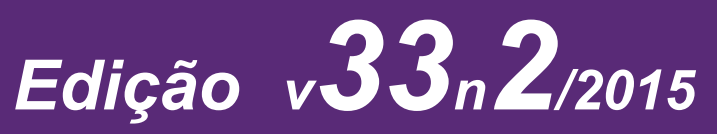

Comunicação e Materialidades 2

MARTINS, Bruno Guimarães. Apropriar-se da materialidade: (re) visitar a história da escrita e do impresso no Brasil. In: Revista Contracampo, v. 33, n. 2, ed. ago-nov, ano 2015. Niterói: Contracampo, 2015. Págs: 44-62.

Contracampo e-ISSN 2238-2577

Niterói (RJ), v. 33, n. 2, ago-nov/2015

www. uff.br/contracampo

A Revista Contracampo é uma revista eletrônica do Programa de PósGraduação em Comunicação da Universidade Federal Fluminense e tem como objetivo contribuir para a reflexão crítica em torno do campo midiático, atuando como espaço de circulação da pesquisa e do pensamento acadêmico. 


\section{Resumo}

Sensíveis às materialidades da comunicação e às diferentes formas de apropriação de mundo "não conceituais" (comer, penetrar e misticismo), assim como formuladas por Gumbrecht para incluir no horizonte da crítica uma perspectiva "não hermenêutica", buscamos no presente artigo compreender a história dos meios de comunicação no contexto brasileiro, especificamente em relação à escrita e aos impressos. Para tanto, nos aproximamos de três diferentes "lições de escrita" (Lévi-Strauss, Derrida e Certeau) que apontam caminhos para perceber como a escrita é apropriada por uma cultura "ágrafa" e de que forma a própria historiografia pode nos fornecer brechas para pensar o "não escrito" da história. Finalmente, buscamos identificar em nossa história alguns exemplos dessas diferentes formas de apropriação que se desviam da interpretação.

Palavras-chave: Materialidade da comunicação; campo não hermenêutico; impresso no Brasil.

\section{Abstract}

Sensitive to materialities of communication and different forms of "non-conceptual" world-appropriation (eating, penetrate and mysticism), as formulated by Gumbrecht to include in the critical horizon a "nonhermeneutics" perspective, we seek to understand in this article the history of the media in the Brazilian context, specifically in relation to the written and printed. In order to do so, we approach three different "writing lessons" (Lévi-Strauss, Derrida and Certeau) that point to ways of understanding how writing is appropriated by a culture which has no written forms, and how historiography itself can provide gaps to grasp the "unwritten" in history. Finally, we seek in our history some examples of appropriation that deviate from interpretation.

Keywords: materiality of communication; non-hermeneutical field; printed in Brazil. 
A materialidade do impresso e a subjetividade moderna

$\mathrm{N}$

a busca de uma construção histórica que leve em conta a compreensão de seus processos de transformação, Hans Ulrich Gumbrecht se afasta da noção de uma história holística, regida por leis que pretendem descrever uma realidade totalizada. Diante das dificuldades para definir um horizonte e as relações entre as várias perspectivas possíveis (econômica, política, cultural, literária, etc.), o autor se apoia em Niklas Luhmann para buscar na "história das formas de comunicação e dos meios de comunicação o substituto funcional para a antiga história em si mesma" (GUMBRECHT, 1998a, p. 71). Foi o conceito de "sistemas sociais", desenvolvido por Luhmann, que conduziu Gumbrecht para uma análise da materialidade dos media como determinante para o sentido. Ao destacar a comunicação na articulação dos sistemas sociais, Luhmann implicaria as transformações dos media em todos os outros subsistemas sociais.

Para exemplificar historicamente as relações entre materialidade e sentido, Gumbrecht (1998) recorre ao século XV, quando a rápida ascensão do Reino de Castela à condição de primeira superpotência de alcance mundial coincide com a substituição dos manuscritos em pergaminho por livros impressos. As prensas tipográficas, cuja presença foi amplamente estimulada pelos reis Fernando e Isabel, realizaram uma ampla "transcrição da vida cotidiana", substituindo os traços do corpo nos manuscritos pelo aparecimento da figura de um autor, cujas intenções se faziam notar nos textos impressos pela recorrência de estilos e ideias. Recuando à Idade Média, para desdobrar seu exemplo, Gumbrecht identifica na consolidação das línguas vernáculas em manuscritos, ao final do século XIII, um primeiro sintoma dessa transformação. Uma vez que a escrita já não era mais executada exclusivamente por clérigos, mas também por um número cada vez maior de escribas leigos, surge uma fratura na divisão tradicional do trabalho. O sentido cosmológico fora deslocado da autoevidência intrínseca à hierarquia religiosa tradicional para um espaço social e comunicativo difuso, em que havia a necessidade de interpretar e explicar o sentido. A despeito dessa relevante modificação, manuscritos vernáculos continuavam a evocar o corpo por meio da caligrafia dos escribas; todavia, tais vestígios se tornariam cada vez menos visíveis nos impressos.

A ambiguidade sugerida por uma antiga denominação da tipografia — black art — mantém na oscilação de sentidos (arte e magia) resquícios de sua dimensão presencial. 
Entretanto, as letras impressas apresentam ao leitor uma voz que, a despeito dos vestígios tipográficos, pretende conduzi-lo até os significados intencionados. Ao mediar um jogo de consciências entre autor e leitor, a disseminação do impresso possibilitou a "ação social à distância", ou seja, era possível comunicação sem presença. Se a leitura do manuscrito era indissociável das singularidades caligráficas e, por vezes, acompanhada pela recitação oral, a impressão tipográfica consolidou o caminho na direção de uma leitura silenciosa. Mesmo que fosse possível e praticada anteriormente, a relação do leitor com letras impressas mecanicamente potencializou e popularizou o aspecto individual e silencioso da leitura. Se concordamos que a regularidade dos tipos móveis inibia a performance corporal na leitura, as intenções do autor deveriam estar explícitas para que fossem interpretadas pelo leitor. Nessa nova configuração, o impresso surge como um medium revestido de intenção, por meio do qual autores se comunicam com a consciência de seus leitores. O declínio da autoridade dos intérpretes e a diversidade dos contextos de recepção despertam a necessidade de se estabelecerem estratégias de interpretação para os textos que circulavam sem a presença de seus autores. A imprensa disseminou um processo de significação que parecia não depender do corpo, fazendo então surgir uma nova estrutura mental para a era moderna: a subjetividade.

\section{Profundidade e superfície}

A conotação negativa de expressões como "leitura superficial" ou "pessoa superficial" indica o valor atribuído à superfície e ao corpo, em oposição à "profundidade espiritual". Uma perspectiva não hermenêutica deseja resgatar à atividade acadêmica o tema da superfície, da materialidade, do corpo e da sensibilidade estética em uma tentativa de superar a supressão do corpo operada pela imprensa. Dessa forma, aspectos estéticos da experiência poderiam ser considerados não apenas na relação com significados, mas em seus movimentos de intensidade. Ao incluir na experiência do mundo a performance do corpo - que sempre interage com alguma materialidade no processo de significação —, o campo não hermenêutico desloca o interesse pela identificação ou pela produção do sentido para a descrição das condições em que o sentido emerge. 
Com a inclusão do campo não hermenêutico no horizonte da crítica, semântica e formas dos conteúdos abrem espaço para "os mutáveis meios de comunicação como elementos constitutivos das estruturas, da articulação e da circulação de sentido" (GUMBRECHT, 1998b, p. 147). As mudanças estruturais pelas quais passam os meios de comunicação provocam um profundo impacto sobre o sentido e suas formas e também reconfiguram as funções dos processos comunicativos, interferindo sobre a mentalidade dos indivíduos envolvidos. Ao relacionar a centralidade da hermenêutica com as transformações no sistema comunicativo, ampliando sua área de influência da crítica para o cotidiano, Gumbrecht posiciona o impresso em um lugar decisivo para se compreender a configuração de uma subjetividade moderna. Tanto nas primeiras formulações das materialidades da comunicação quanto na configuração do campo não hermenêutico e seus desdobramentos para o conceito de "produção de presença", o deslocamento epistemológico sugerido por Gumbrecht destaca uma noção central de emergência, enfraquecendo a centralidade do sujeito na produção de saber. Ao localizar historicamente a emergência da figura epistemológica do observador de segundo grau, indicando como marco para sua inevitabilidade o século XIX, o autor pretende, com base em seu paradoxo, observá-la e questionar sua própria validade. Se o início da modernidade opera a separação entre corpo e espírito, fazendo surgir uma distância entre aquele que observa e o que é observado, um segundo momento de modernidade epistemológica inverte a operação ao transformar sujeito em objeto. O termo alemão para ciências humanas é revelador, pois Geisteswissenschaften pode ser traduzido como "ciências do espírito". Nesse sentido, as ciências humanas são um sintoma do surgimento de uma nova figura epistemológica, o observador de segunda ordem, ou seja, aquele que se auto-observa no ato de observação.

A institucionalização do observador de segunda ordem questiona e torna mais complexa a produção do conhecimento, distinguindo-se de uma orientação positivista de criar um contexto livre de contradições. Como efeito da autorreflexão revela-se uma infinidade de pontos de vista, um "poliperspectivismo", que produz uma desconfortável sensação de perda do referente cujo efeito, notado em outro contexto, é de certa "vertigem de relatividade". A solução que se apresenta para tal instabilidade no âmbito da narrativa é a figura do autor, capaz de compor e integrar uma grande multiplicidade de pontos de vista. É nesse sentido que, ao privilegiar uma apropriação conceitual, as ciências que têm como objeto o homem, ou seja, o sujeito, afastam-se dos aspectos 
sensíveis do mundo. A partir de então, para algo se mostrar verdadeiro dependeria de um afastamento de aspectos "corporais" do fenômeno observado. Foi simultaneamente a essas transformações que deram origem às "ciências humanas" quando se iniciou um sistema de comunicação impressa no Brasil. Portanto, considerando-se um passado précolonial e colonial sem prensas, acreditamos que uma perspectiva "não hermenêutica" pode fornecer um horizonte conceitual adequado para compreender a apropriação da imprensa e dos impressos no cotidiano brasileiro oitocentista, que nos parece distante de se caracterizar como "campo hermenêutico".

\section{Diferentes formas de apropriação}

Buscando seguir com aquilo que defende ser o mais importante legado de uma "estética da recepção", Gumbrecht desdobra sua distinção de cultura de uma tipologia binária — "cultura de sentido" e "cultura de presença" — em quatro diferentes formas de apropriação de mundo, apresentadas desde um tipo ideal da cultura de presença até a sua polaridade oposta, uma cultura de sentido total. Tais tipologias pretendem inspirar "imagens e conceitos que nos ajudem a captar as componentes não interpretativas da nossa relação com o mundo" (GUMBRECHT, 2004, p. 114). Nesse sentido, o autor aponta que a forma mais direta de trazer as coisas do mundo à tangibilidade da presença é comê-las (eating the things of the world). Comer é um modo óbvio e crucial de se apropriar do mundo, como na celebração da eucaristia católica, quando se come o corpo e se bebe o sangue de Cristo. Uma segunda forma de apropriação se constitui ao se penetrar coisas e corpos, momento no qual "a fusão de corpos com outros corpos ou com coisas inanimadas é sempre transitória e, por isso, abre necessariamente um espaço de distância ao desejo e à reflexão" (GUMBRECHT, 2004, p. 115). O ato de se apropriar "penetrando" implica obviamente em uma relação corporal. Em uma terceira forma de apropriação de mundo característica da cultura de presença, quando a presença do mundo (ou de um outro) é sentida fisicamente sem, no entanto, identificar-se ou perceber o objeto que originou tal sentimento, temos o misticismo.

Essas três formas de apropriação que acabamos de descrever realizam no diagrama binário do autor um afastamento progressivo de uma cultura de presença em direção a uma 
cultura de sentido. Em um curioso movimento, essas formas de apropriação são negadas pela formulação de regras que pretendem preservar seus agentes do medo despertado por elas, a saber, o medo de ser comido, o medo de ser penetrado ou violado e o medo de perder o controle sobre si mesmo. Por fim, os elementos que caracterizam a forma de apropriação exclusivamente espiritual, no polo de uma cultura de sentido, são a interpretação e a comunicação. Esta última forma de apropriação é típica para uma sociedade letrada, quando o texto impresso realiza a mediação entre as intenções de um autor e a consciência de um leitor. Para a cultura de sentido, o medo da apropriação se manifesta na possibilidade de uma "comunicação total", uma situação em que todos os sentimentos e pensamentos mais profundos estão acessíveis a quaisquer outros.

Todo esforço tipológico se traduz em uma tentativa de sugerir conceitos que sejam capazes de aproximar a crítica de aspectos não conceituais da experiência obscurecidos pela institucionalização de uma lógica interpretativa pelo campo hermenêutico. Se em uma cultura de sentido a interpretação rege as relações com o mundo, suprimindo a superfície em busca da profundidade, em uma cultura da presença é justamente aquilo que é tangível ao corpo - "produção de presença" — o que comanda as mesmas relações. Vamos colocar agora tipologia a serviço do artigo. Interessa-nos compreender como a escrita e a imprensa, medium característico de uma cultura de sentido, reagiram (e ainda reagem) a formas de apropriação típicas de uma cultura de presença que, acreditamos, caracterizava (e ainda caracteriza) o cotidiano brasileiro.

\section{Lição de escrita}

Quando não há condições para que se realizem "pontes” entre consciências distintas, que sentido é produzido na leitura de um texto impresso? Ou seja, se um texto não tem o seu sentido interpretado ou comunicado, o que ele significa? E mais, como ele significa? Que tipo de apropriação se configura diante de uma técnica cuja origem e sentidos se desconhece? De que maneira as formas de apropriação típicas de uma cultura de presença reagem diante da escrita e do impresso? Para formular respostas às questões, vamos inicialmente aprender algumas "lições" de um campo em que se desenham as fronteiras entre cultura de sentido e cultura de presença, a etnografia. 
Em um fascinante capítulo de Tristes Trópicos, intitulado sugestivamente "Lição de escrita", Lévi-Strauss relata um "incidente extraordinário" quando a escrita — ferramenta que produz a estratégia narrativa do antropólogo — é apropriada pelos indígenas. Vamos à descrição de tal "incidente":

Insisti com o chefe para que procedesse as trocas sem demora. É então que ocorre um incidente extraordinário que me obriga a voltar um pouco atrás. É de imaginar que os Nambiquara não sabem escrever; tampouco desenham, com exceção de alguns pontilhados ou ziguezagues nas suas cuias. Porém [...] distribuí folhas de papel e lápis com os quais, de início, nada fizeram; depois, certo dia vi-os muito atarefados em traçar no papel linhas horizontais onduladas. Que queriam fazer, afinal? Tive que me render à evidência: escreviam, ou, mais exatamente procuravam dar a seu lápis o mesmo uso que eu, o único que então podiam conceber [...]. Para a maioria, o esforço parava por aí; mas o chefe do bando enxergava mais longe. Era provável que só ele tivesse compreendido a função da escrita. Assim, exige de mim um bloco e nos equipamos da mesma forma quando trabalhamos juntos. Não me comunicava verbalmente as informações que lhe peço, mas traça no seu papel linhas sinuosas e me mostra, como se ali eu devesse ler a sua resposta. Ele próprio se deixa tapear um pouco com sua encenação; toda vez que sua mão termina uma linha, examina-a ansioso como se dela devesse surgir algum significado, e a mesma desilusão se estampa em seu rosto. Mas não a admite; e está tacitamente combinado entre nós que a sua garatuja tem um sentido que finjo decifrar; o comentário verbal segue-se quase de imediato e dispensa-me de exigir os esclarecimentos necessários. Ora, mal ele reunira todo o seu pessoal, tirou do cesto um papel coberto de linhas tortuosas que fingiu ler e nas quais procurava, com uma indecisão afetada, a lista de objetos que eu devia dar em troca dos presentes oferecidos: a este, contra um arco e flechas, uma faca de arrasto! ao outro, contas! para os seus colares... Essa encenação prolongou-se por duas horas. Que esperava ele? Enganar a si mesmo, talvez; mais porém, surpreender seus companheiros, 
convencê-los de que tinha participado na escolha das mercadorias, que obtivera a aliança com o branco e que partilhava seus segredos (LÉVISTRAUSS, 1996, p. 280).

Apesar de Lévi-Strauss direcionar sua análise para o que identifica como uma função estrutural de dominação dos povos exercida pela escrita, desejamos inicialmente nos concentrar no ato de apropriação da escrita pelos Nhambiquara e, mais especificamente, na encenação do chefe que "se deixa tapear um pouco" pelo que escreve. De acordo com a descrição do antropólogo, ele parece atribuir certo poder mágico a essa prática de que desconhece a origem ou os significados. Incapaz de interpretar os significados da escrita, mas desconfiando de sua potência significante, o chefe mimetiza a escrita, reposicionando-a em seu universo simbólico. Ao fingir ler, o chefe conduzia um roteiro improvisado, realizado na fala, mas guiado pela encenação da escrita. Muito nos interessa a percepção da expectativa do chefe de "enganar a si mesmo", pois daí parecem surgir os desdobramentos mais interessantes nessa apropriação. $\mathrm{O}$ autoengano possui uma dupla função: subjetivamente, ameniza as frustrações decorrentes da não compreensão de seus significados; objetivamente, é compensado pela eficácia persuasiva da própria encenação. O episódio ilustra as impurezas das formas de apropriação, sobrepondo a percepção mística da escrita a uma espécie de digestão da ferramenta para que aquilo que não se compreende seja capaz de produzir significado.

\section{Lição da lição}

Relembramos aqui as críticas feitas por Derrida à Lição de escrita, revelando, surpreendentemente, que Lévi-Strauss faz parte de um "etnocentrismo pensando-se ao contrário como antietnocentrismo" (DERRIDA, 1973, p. 148, grifo do autor). Ao problematizar vigorosamente a noção de "escritura", reconhecendo o jogo de diferenças na fala, Derrida acusa na retórica literária de a Lição de Lévi-Strauss um gesto que "separa a machado a escritura da fala", gesto que acompanha a distinção formulada por Saussure. Derrida afirma que ao contrapor a encenação da inocência original de um povo "sem escritura", sem história e sem maldade, um povo que não teria sido 
"violentado" pela escrita, o etnógrafo incorre no risco de suprimir as diferenças que busca descrever. De acordo com Derrida, ao não problematizar o conceito de escritura, LéviStrauss desconsidera uma "arquiescritura" da fala e das ações de escrever — os "riscos e zigue-zagues" dos Nhambiquara - que não se encaixam em representações de um alfabeto fonético. Ao atribuir à escritura um valor negativo, mantendo, oportunamente para sua argumentação, uma distinção entre os povos históricos e os povos sem história, desprezaria qualquer potência emancipatória da escrita, que estaria perpetuamente ligada à dominação do homem pelo homem.

O que é a "Lição de escritura"?

Lição em um duplo sentido e o título é belo por mantê-lo reunido. Lição de escritura, pois é de escritura ensinada que se trata. O chefe Nhambiquara aprende a escritura do etnógrafo, aprende-a sem compreender; mais propriamente ele mimica a escritura do que compreende a sua função de linguagem, ou melhor, compreende o seu funcionamento, aqui acessório, de comunicação, de significação, de tradição de um significado. Mas a lição de escritura é também lição da escritura; ensinamento que o etnólogo acredita poder induzir do incidente no curso de uma longa meditação, quando, lutando, diz ele, contra a insônia, reflete sobre a origem, a função e o sentido da escritura. Tendo ensinado o gesto de escrever a um chefe Nhambiquara que aprendia sem compreender, o etnólogo, por sua vez, compreende então o que ele lhe ensinou e tira a lição da escritura. (DERRIDA, 1973, p. 150)

Depois de revelar como o "incidente extraordinário" poderia ser lido como uma parábola que remete às funções da escritura desde as suas origens ("a hierarquização, a função econômica da mediação e da capitalização, a participação em um segredo quasereligioso"), Derrida busca pela lição de a Lição. Tal lição implica em reconhecer que a estrutura presente de uma "arquiescritura" estaria disponível ao chefe Nhambiquara para que ele se apropriasse tão imediatamente da escritura. Sendo assim, seria necessário integrar à fala não escrita a violência e o jogo de diferenças da escritura, possibilitando aos Nhambiquara, ou seja, ao povo sem história, participar de um conhecimento e uma linguagem que possuem implicações intelectuais e teóricas. 


\section{Lição outra}

Parafraseando Lévi-Strauss, Michel de Certeau também busca por uma "lição de escrita" em Histoire d'un voyage fait a la terre du Brésil, relato da experiência do jovem seminarista Jean de Léry, que se aventurou entre os Tupinambás na Baía de Guanabara entre 1556 e 1558. Depois de identificar um conjunto de noções que no século XVII definem pela primeira vez etnologia - oralidade, espacialidade, alteridade, inconsciência configurando uma ciência que se interessa "pelo que não está escrito", em contraposição ao surgimento simultâneo de noções que baseiam a historiografia moderna (escrita, temporalidade, identidade, consciência), Certeau busca em um movimento de autorreflexão "o que o escrito diz da palavra", ou seja, a presença da voz na escrita:

Interrogo-me sobre o alcance dessa palavra instituída no lugar do outro e destinada a ser escutada de uma forma diferente da que fala. Esse espaço da diferença questiona um funcionamento da palavra nas nossas sociedades da escrita [...] (CERTEAU, 2006, p. 212, grifos do autor).

A despeito de suas suposições implícitas sobre a oralidade, na escrita etnográfica é possível entrever vestígios da "palavra", a presença de um outro se entrincheira em suas linhas. Certeau lê os relatos de Léry como uma cena etnográfica primitiva. Notando que foram publicados pela primeira vez em 1578, os relatos situam-se com transições das margens da modernidade. Se a diferença entre "eles" e "nós" já se encontrava marcada pela escrita, o frescor das narrativas desse protoetnógrafo nos permitiria ler tanto a operação escriturária circular de afirmação da identidade de um "mesmo" quanto os desvios da fabulação errante da voz de um "outro". A "lição de escrita" em Léry se mostra, por um lado, pela função estratégica do relato de viagem, como afirmação do "mesmo"; e, por outro lado, a fascinação prazerosa que o narrador demonstra pela "palavra tupi" provoca um "buraco no tempo" devido à sua ausência de sentido, abrindo, assim, uma brecha para a manifestação da voz de um "outro".

Uma tal alegria [escreve Jean de Léry, a propósito de suas impressões no decorrer de uma assembleia tupi] que não apenas ouvindo os acordes tão 
bem medidos de um tal multidão, e sobretudo pela cadência e pelo refrão da balada, a cada estrofe todos conduziam vozes dizendo: heu, heuaüre, heüra, heüraüre, heüra, heüra, oueh, fiquei inteiramente encantado; mas também todas as outras vezes que me lembro disto, o coração sobressaltado, me parece que ainda os tenho nos ouvidos. (LÉRY apud CERTEAU, 2006, p. 215 , grifos do autor)

Lançando mão da psicanálise para compreender a "Histoire", Certeau identifica que o sucesso da escrita em reproduzir o "mesmo" provoca um efeito secundário não desejado, um dejeto, uma recaída, um "resto", que finalmente remete ao "outro". A palavra sedutora, que se aproxima do "selvagem" em sua distinção ao "civilizado", erotiza seu corpo, sua nudez, sua voz. A sedução do corpo selvagem promove uma abertura da escrita aos prazeres do significante, deparando-se com a dificuldade em representar o outro resta na escrita, o "inter-dito", o que fornece subsídio para a revisão e para a imaginação historiográfica.

\section{Lições aplicadas}

Em uma fascinante investigação histórica sobre o fenômeno chamado "santidade indígena”, ao final do século XVI, Ronaldo Vainfas descreve a apropriação da catequese jesuíta realizada pelos Tupinambás, fazendo surgir uma "idolatria insurgente" que mobilizou algumas centenas de indivíduos em torno da busca de uma "Terra Sem Mal", espécie de paraíso mitológico tupi onde se encontraria uma fartura infinita sem trabalho e sem escravidão. Partindo de relatos da Inquisição portuguesa, o historiador revela como esses grupos messiânicos desenvolveram práticas e discursos de resistência à catequese e à escravidão. É interessante notar o registro de uma sacerdotisa, uma líder feminina, que inverte tanto a hierarquia convencional da religião católica quanto da organização social tupinambá, indicando um duplo movimento de transformação. Também é importante lembrar que além de Tupinambás e caboclos, os inquisidores notam a participação de portugueses (homens e mulheres) nos rituais, comprovando a sedução exercida pela "Santidade". As menções à catequese dos líderes da Santidade indicam que eles tinham algum conhecimento da escrita e dos rituais católicos, que sincretizaram ao seu modo. 
Um detalhe nos rituais da Santidade, quando se entoavam cânticos junto ao consumo de tabaco e cauim, mostrou-se particularmente interessante: a presença de "tabuinhas" com inscrições indecifráveis em suas "igrejas":

Contou Simão Dias que, à porta do terreiro, na casa erigida como igreja dos índios, ficava uma cruz de pau; e no interior, penduradas pelas paredes, viam-se diversas tabuinhas de madeiras, pintadas com riscados "que eles diziam serem seus livros”. E no centro do terreiro, aparecia uma estaca alta de madeira enterrada no chão, sobre a qual se postava o ídolo, "que tinha uma cara figurada com olhos e nariz, enfeitado com paninhos velhos". (VAINFAS, 1995, p. 130)

O que podemos deduzir dessas "tabuinhas" com base nas descrições do historiador? Sabemos que elas faziam parte de uma simbologia ritual, quando eram provavelmente "lidas" ou "cantadas" pelos seus participantes. No entanto, o que se escrevia ali? As inscrições não foram compreendidas pelos acusados da Inquisição, alguns deles alfabetizados. É provável que tais inscrições se aproximassem dos riscos e zigue-zagues dos Nhambiquara. Para "ler" essas "tabuinhas" da Santidade, talvez seja necessário seguir tanto os questionamentos de Derrida a respeito do conceito de escritura quanto escutar a voz do outro, como aponta Michel de Certeau. Se, por um lado, as inscrições das "tabuinhas" parecem modular uma pura representação rítmica, algo sem "sentido", por outro lado, podemos deduzir que seu uso no ritual - independentemente do que estivesse ali "escrito" - simultaneamente marcava a identidade e afirmava a diferença da Santidade em relação à igreja que pretendia mimetizar.

Se nas "lições de escrita" as tipologias da cultura parecem claramente distintas, o mesmo não se repete no Brasil oitocentista, pois lá encontramos justaposições, hibridizações e distorções que marcam as apropriações de um novo espaço das letras. Entretanto, insistindo na hipótese de que a cultura brasileira mantém formas de apropriação típicas de uma cultura de presença, vamos tentar identificá-las. Em primeiro lugar, como podemos identificar o comer? Da antropofagia praticada pelos Tupinambás ao Manifesto Antropófago, essa forma primordial de se apropriar das coisas do mundo parece atravessar a cultura brasileira. De forma geral, poderíamos dizer que o "atraso" na produção das letras nacionais dispôs 
um cardápio variado de "originais" a serem deglutidos e digeridos. Podemos compreender o Manifesto como uma reflexão da literatura brasileira, que buscava, no início do século $\mathrm{XX}$, relacionar-se com as novas teorias e vanguardas europeias. Porém, se as chamadas vanguardas históricas questionavam a "instituição arte", o que questionar aqui, diante da nossa conhecida fragilidade institucional? Era necessário dar um passo atrás, voltar às origens e à história das origens, voltar, então, à escrita da história para reescrevê-la, para reintroduzir a oralidade esquecida da língua geral, fazer da palavra morta palavra viva na performance de um manifesto, inventar uma nova história e uma nova literatura. Nesse sentido, a ânsia de devoração voltava-se não só contra os modelos estrangeiros, mas contra a própria escrita, reivindicando-se a oralidade das raízes indígenas e da influência africana. Em sua formulação poético-panfletária, ao lançar-se contra as instituições o Manifesto deseja escutar os vestígios do oral na história. Para que o mundo fosse levado à boca, buscando sabores e prazeres sensíveis ao corpo, era necessário recusar separações: “O espírito recusa-se a conceber o espírito sem o corpo. O antropomorfismo. Necessidade da vacina antropofágica. Para o equilíbrio contra as religiões de meridiano. E as inquisições exteriores. Só podemos atender ao mundo orecular" (ANDRADE, 2001, p. 48, grifo meu).

Porém, antes dessa energia iconoclástica fazer com que a vanguarda tupiniquim voltasse seus ouvidos ao passado, lemos no artigo de abertura d'A Marmota na Corte a primeira variante das folhas publicadas pelo editor pioneiro Francisco de Paula Brito (sucederam a Marmota Fluminense e A Marmota), metáforas que associam diretamente linguagem, pensamento e, especialmente, os prazeres da leitura ao paladar, como se dissessem: "ler é comer". É importante destacar que para o público oitocentista, pouco habituado à leitura e à imprensa, o didatismo da associação estabelecia para o impresso um tempo e um espaço no cotidiano:

Essa folha há de ser um guisadinho saboroso, e bem temperado por tal forma que faça os leitores ou convidados dela lamberem os beiços e pedirem repetição da dose: há de ser um pudim de cousas boas, já de levar o leite da verdade, o pão da religião, os ovos das pilhérias, o cidrão da lei, as passas da poesia, a noz moscada da crítica, e por fim a canela da decência para aromatizar o paladar das famílias, e dar uma vista agradável ao bolo. Ora pois, abram a boca e fechem os olhos para chuparem o petisco. (A Marmota na Corte, n. 1,7 set. 1849) 
E quanto ao penetrar? Não seria essa também uma forma de apropriação resiliente na cultura brasileira, cuja manifestação mais notável é a hipertrofia do privado em relação ao público? Seja em capítulos de história política ou no noticiário contemporâneo, a dificuldade em se distinguir entre o público e o privado é uma constante. Tudo aquilo que deveria ser público é frequentemente penetrado por interesses privados. Ora, o "homem cordial" é justamente aquele que penetra o espaço público com suas relações personalizadas, seus interesses privados e seus afetos. Se o impresso suprime a presença, o que ele diz a este homem que vislumbra o horror na impessoalidade e na distância? João Cezar de Castro Rocha desenvolve, em Literatura e Cordialidade (1998), uma "teoria do espaço público brasileiro" em que aponta a polêmica pessoal, no contexto literário de meados do século XIX, como uma estratégia para o homem de letras "cordial" penetrar a esfera pública literária. A cordialidade das relações desfavorecia o exercício de uma crítica autônoma, valorizando a oratória em contraste ao ajuizamento e à argumentação, o que conferiria um forte caráter oral ao nosso sistema literário. Trata-se, ao menos aos olhos da crítica, de uma (inter)penetração entre formas de conhecimento aparentemente distintas, a oralidade e a escrita. Lembremos, ainda, que, pouco tempo depois de uma curta exclusividade da Imprensa Régia, houve no período da Independência uma numerosa proliferação de pasquins, descritos como "insultos impressos". Dedicados, em sua maioria, a violentos ataques pessoais, os pasquins pré-independência escondiam-se sob o anonimato e tinham em sua efemeridade a confirmação de seus métodos unidirecionais. Dessa forma, poderíamos dizer que a constituição de uma esfera de discussão pública na imprensa foi marcada pela violência dos ataques pessoais e pela defesa de interesses privados, algo mais próximo de uma luta corporal do que de uma batalha conceitual entre diferentes ideias e perspectivas.

Vejamos agora o misticismo como forma de apropriação da escrita e dos impressos. Na Colônia sem prensas, a raridade da escrita e da imprensa conferia a seus objetos certa aura mística, a dificuldade de se imaginar sua origem reafirmava o poder daqueles capazes de produzir ou atualizar escritos. Ao descrever a relação de proximidade corporal intensa que o cristianismo luso-brasileiro manteve com os santos, pouco usual e "inadequada", Gilberto Freyre identifica claramente um uso místico para a escrita:

tinha-se tanta liberdade com os santos que era a eles que se confiava a guarda das terrinas de doce e de melado contra as formigas: 
- "Em louvor de S. Bento

que não venham as formigas

cá dentro",

escrevia-se num papel que se deixava à porta do guarda comidas. (FREYRE, 1969, p. XLII)

Nesse manuscrito a função pragmática de proteger o alimento prevalece, a escrita se investe de uma qualidade presencial mágica cuja voz seria capaz de afugentar os insetos. Há nesse exemplo um curioso endereçamento animal: seriam as formigas capazes de decifrar tal pedaço de papel? Obviamente que não. Mas, então, poderiam elas ouvi-lo? O absurdo da questão pode nos levar à compreensão do que está em jogo nesse pequeno pedaço de papel. A escrita não é compreendida como medium capaz de transmitir intenções subjetivas, funciona principalmente para a invocação da voz. Em outro exemplo, Freyre aponta para a persistência da percepção mágica do manuscrito quando o sobrado se estabelece como primeiro sintoma de urbanização. Ao identificar o valor supersticioso atribuído a plantas, aves e outros animais nas varandas e nos quintais dos sobrados, pedaços de papel ocupam uma vez mais sua função místico-pragmática: "E convém não nos esquecermos dos papéis com orações também profiláticas - guardando a casa de cidade dos perigos de ladrões, de peste, de malfeitor - que se pregavam às portas e às paredes" (FREYRE, 1961, p. 227). Tal função mística ainda resiste nos dias de hoje como, por exemplo, na impressão de folhetos e santinhos fúnebres que invocam pela presença do morto.

Bem sabemos que a capital da corte em meados do século XIX não era habitada por Nhambiquaras ou por Tupinambás, mas algo das "lições de escrita" permaneceu no desenho de uma "cidade das letras". Em uma instigante reflexão identificando de que forma as "práticas escriturárias" manifestaram-se conformando não só o imaginário, mas o espaço urbano na América Latina, reproduzindo-se a ordem centralizadora desejada pelo colonizador, o crítico uruguaio Ángel Rama identifica com pertinência resquícios de magia na prática do escrivão que realizava a partilha das propriedades:

Pensar a cidade competia a esses instrumentos simbólicos [palavras e diagramas gráficos] que estavam adquirindo sua pronta autonomia, que os adequaria ainda melhor às funções que lhes reclamava o poder absoluto. 
Apesar de que se continuou aplicando um ritual impregnado de magia para assegurar a posse do solo, as ordenanças reclamaram a participação de um script (em qualquer de suas expressões divergentes: um escrivão, um escrevente ou um escritor) para redigir uma escritura. A este se conferia a alta missão que se reservou sempre aos escrivães dar fé, uma fé que só poderia proceder da palavra escrita, que iniciou sua esplendorosa carreira imperial no continente. (RAMA, 1984, p. 29)

Buscamos apresentar alguns exemplos que se desviam da interpretação e da comunicação como forma de apropriação e demonstram a presença do comer, do penetrar e do misticismo como formas de apropriação do impresso e da imprensa. É importante ressaltar que essa dificuldade não se restringia aos poucos letrados e iletrados, mas podia ser percebida também no mais privilegiado leitor:

O imperador dizia gostar dos livros com a satisfação dos cinco sentidos, isto é: visual, pela impressão exterior ou aspecto do livro; tátil, ao manusear-lhe a maciez ou aspereza das páginas; auditivo, pelo brando crepitar ao folheá-lo;

olfativo, pelo cheiro pronunciado do papel impresso ou fino couro da encadernação;

gustativo, isto é, o sabor intelectual do livro, ou mesmo físico, ao umedecerlhe ligeiramente as pontas das folhas para virá-las. (HOLANDA, 1955, p. 180)

A citação mostra que o fetichismo que delicia o Imperador Pedro II indica uma relação sensual com o livro que não se limitava à transmissão das ideias de um autor. Ao destacar as qualidades físicas do objeto impresso, observamos um relevante. Ao não ser tipicamente interpretado, a materialidade se reveste de sentidos, o corpo se faz presente no texto e no ato de leitura. A ingenuidade objetiva do observador sem corpo não teria lugar em um observador que necessariamente se auto-observa durante a observação, notando inevitavelmente sua posição, seu corpo. Em parte, parece ser justamente o movimento de autopercepção o que caracteriza nosso nobre leitor, contudo não se trata de um aspecto reflexivo que ocorre à consciência, mas de uma interpelação corporal ao ato de leitura, um corpo-fantasma que assombra e interfere nos sentidos do impresso. 


\section{Referências}

ANDRADE, Oswald de. A utopia antropofágica. São Paulo: Globo, 2001.

BERGER, Peter; LUCKMANN, Thomas. A Construção Social da Realidade. Petrópolis: Vozes, 2002.

BÜRGER, Peter. Teoria da Vanguarda. Tradução José Pedro Antunes. São Paulo: Cosac Naify, 2008.

CERTEAU, Michel de. A escrita da história. Tradução Maria de Lourdes Menezes. Rio de Janeiro: Forense Universitária, 2006.

DERRIDA, Jacques. Gramatologia. Tradução Miriam Schnaiderman e Renato Janine Ribeiro. São Paulo: Perspectiva, Editora da Universidade de São Paulo, 1973.

EISEINSTEIN, Elizabeth. The printing press as an agent of change. Communications and cultural transformation in early-modern Europe. Cambridge: Cambridge University Press, 1979.

FREYRE, Gilberto. Casa grande \& Senzala. Formação da família brasileira sob o regime de economia patriarcal. 1o tomo. Rio de Janeiro: José Olympio, 1969.

. Sobrados e mucambos. Decadência do patriarcado rural e desenvolvimento do urbano. 1o tomo. Rio de Janeiro: José Olympio, 1961.

GUMBRECHT, Hans Ulrich. Modernização dos sentidos. São Paulo: Ed. 34, 1998 a.

. O campo não-hermenêutico ou a materialidade da comunicação. In: Corpo e forma. Ensaios para uma crítica não-hermenêutica. Rio de Janeiro: EdUERJ, 1998 b.

. Materialidades de Comunicação: viagem de uma intuição. In: SÜSSEKIND, Flora; DIAS, Tânia (orgs.). A historiografia literária e as técnicas de escrita. Rio de Janeiro: Edições Casa de Rui Barbosa, Vieria e Lent, 2004b.

Press, 2004a.

. Production of presence. What meaning cannot convey. Stanford: Stanford University

GUMBRECHT, Hans Ulrich; PFEIFFER, Karl Ludwig. (orgs.). Materialities of Communication. Translated by William Whobrey. Stanford: Stanford University Press, 1994.

HOLANDA, Sérgio Buarque de. Capítulos de literatura colonial. São Paulo: Brasiliense, 2000.

Raízes do Brasil. São Paulo: Companhia das Letras, 2006 [1936]. 
LAJOLO, Marisa; ZILBERMAN, Regina. A formação da leitura no Brasil. São Paulo: Editora Ática, 1998.

LÉVI-STRAUSS, Claude. Tristes trópicos. Tradução Rosa Freire d'Aguiar. São Paulo: Companhia da Letras, 1996.

LUHMANN, Niklas. A realidade dos meios de comunicação. Tradução Ciro Marcondes Filho. São Paulo: Paulus, 2005.

LUSTOSA, Isabel. Insultos impressos. A guerra dos jornalistas na independência (18211823). São Paulo: Companhia das Letras, 2000.

RAMA, Angel. A cidade das letras. São Paulo: Brasiliense, 1984.

RIZZINI, Carlos. O livro, o jornal e a tipografia no Brasil. 1500-1822. Com um breve estudo geral sobre a informação. São Paulo, Imprensa Oficial: 1988 [1946].

ROCHA, João Cezar de Castro. Introdução. In: GUMBRECHT, Hans Ulrich. Corpo e forma: ensaios para uma crítica não-hermenêutica. Rio de Janeiro: EdUERJ, 1998a

Literatura e cordialidade. O público e o privado na cultura brasileira. Rio de Janeiro: EdUERJ, 1998b.

VAINFAS, Ronaldo. A heresia dos índios. Catolicismo e rebeldia no Brasil colonial. São Paulo: Companhia das Letras, 1995. 